\title{
Total Fertility Rates, by Maternal Educational Attainment and Race and Hispanic Origin: United States, 2019
}

\author{
by Brady E. Hamilton, Ph.D., Division of Vital Statistics
}

\section{Abstract}

Objective-This report presents 2019 total fertility rates for the United States, by educational attainment and race and Hispanic origin of mother.

Methods-Descriptive tabulations of the total fertility rate by educational attainment of mother for the United States are presented and described. The total fertility rate is the average number of children a group of women would expect to have at the end of their reproductive lifetimes. Data are based on the 2003 revision of the U.S. Standard Certificate of Live Birth.

Results - In 2019, the U.S. total fertility rate (TFR) for all women aged 15-49 was 1,705 expected births per 1,000 women. TFRs decreased as level of education increased from women with a 12th grade education or less through an associate's and bachelor's degree, and then rose from bachelor's degree through a doctorate or professional degree. Among the race and Hispanicorigin groups, TFRs were highest for Hispanic women $(1,939)$, followed by non-Hispanic black $(1,774)$ and non-Hispanic white $(1,610)$ women. Rates generally declined from the lowest educational level through a bachelor's degree for non-Hispanic white women, and through an associate's degree for Hispanic women, and then generally rose for both groups for women with advanced degrees. TFRs for non-Hispanic black women declined by educational level through a master's degree. Across the race and Hispanic-origin groups, the lowest TFR by educational level was for non-Hispanic black women with a master's degree $(1,038)$, and the highest was for Hispanic women with a 12th grade education or less $(3,025)$. TFRs for non-Hispanic black and Hispanic women with some college credit or less were generally higher than the rates for non-Hispanic white women, but TFRs for non-Hispanic black and Hispanic women with a master's degree or more were generally lower than the rates for non-Hispanic white women.
Keywords: education and fertility $\bullet$ maternal race and Hispanic origin $\bullet$ National Vital Statistics System

\section{Introduction}

Educational attainment is considered an important measure of socioeconomic status and can be useful in interpreting patterns and differences in fertility behavior overall and among population groups. Maternal education has been shown to be associated with contraceptive use, the timing of childbearing, and the total number of children women have in their lifetimes (1-4).

National data on the educational attainment of women giving birth in the United States became available again in 2016 with national implementation of the 2003 revision of the U.S. Standard Certificate of Live Birth across the United States (4-6). Data on educational attainment from the 2003 birth certificate revision are not considered comparable with data from the 1989 revision (7) and, accordingly, data for the two revisions were not combined by the National Center for Health Statistics (NCHS) to produce national data. This report is the first from NCHS to publish vital statistics-based fertility rates by educational attainment of mother for the United States in more than 20 years $(3,4)$. This report presents total fertility rates (TFRs) by educational attainment of the mother by selected race and Hispanic-origin groups for 2019.

\section{Methods}

Data shown in this report are based on $100 \%$ of births registered to residents of the 50 states and the District of Columbia for $2019(8,9)$. Data are based on the 2003 U.S. Standard Certificate of Live Birth (10), which was implemented

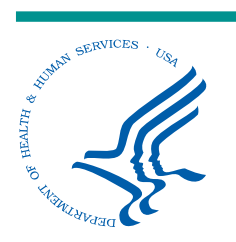

U.S. DEPARTMENT OF HEALTH AND HUMAN SERVICES 
by all reporting areas as of January 1, 2016. Data are provided to NCHS through the Vital Statistics Cooperative Program (9).

Educational attainment of the mother is based on the Mother's Education item on the 2003 U.S. Standard Certificate of Live Birth $(10,11)$. This item is completed by the mother or her surrogate and asks for the highest degree or level of school completed at the time of delivery and includes eight response categories:

- 8th grade or less;

- 9th-12th grade, no diploma;

- High school graduate or GED completed;

- Some college credit but no degree;

- Associate's degree, including Associate of Arts (A.A.) and Associate of Science (A.S.);

- Bachelor's degree, including Bachelor of Arts (B.A. or A.B.) and Bachelor of Science (B.S.);

- Master's degree, including Master of Arts (M.A.), Master of Science (M.S.), Master of Engineering (M.Eng.), Master of Education (M.Ed.), Master of Social Work (M.S.W.), and Master of Business Administration (M.B.A); and

- Doctorate, including Doctor of Philosophy (Ph.D.) and Doctor of Education (Ed.D.), or professional degree, including Doctor of Medicine (M.D.), Doctor of Dental Surgery (D.D.S.), Doctor of Veterinary Medicine (D.V.M.), Doctor of Laws (LL.D.), and Juris Doctor (J.D.).

In this report, the educational categories 8th grade or less and 9th-12th grade, no diploma have been combined to represent women who have not graduated from high school.

Race and Hispanic origin are reported separately on the birth certificate. Data by race and Hispanic origin are based on the 1997 Office of Management and Budget, or OMB, standards (12) and are shown for the three largest groups: non-Hispanic, single-race white; non-Hispanic, single-race black; and Hispanic. For detailed information on Hispanic origin and the processing and tabulation of data by race, see the "User Guide to the 2019 Natality Public Use File" (9).

While birth counts are based on $100 \%$ of births registered in the United States, and are therefore complete, completeness of reporting (that is, missing information) differs by certificate item. For $2019,1.4 \%$ of birth records were missing information on the educational attainment of the mother. Missing information on age $(0.01 \%)$ and race $(6.8 \%)$ of mother was imputed, per NCHS standard procedures (9). Hispanic origin of the mother was not reported for $1.0 \%$ of all birth records in 2019 (9).

The total fertility rate is the expected number of births a group of women would have by the end of their reproductive lifetimes if the age-specific birth rates in a given year continued throughout their childbearing years. The rate is the sum of the age-specific birth rates (for the 5 -year age groups from 15 through 49 for this report) multiplied by 5 and can be expressed as the average expected number of children that would be born per 1,000 women. Women for whom Hispanic origin is unknown $(1.0 \%)$ were classified as non-Hispanic. Records with educational attainment not stated $(1.4 \%)$ were distributed in the same proportions as those of known educational attainment within each age and race and Hispanic-origin category in computing the age-specific birth rates.
The TFRs by educational attainment shown in this report are based on population estimates by education level, age, and race and Hispanic origin of women aged 15-49 for 2019 available from the March Annual Social and Economic Supplement (ASEC) of the Current Population Survey (CPS) (13). Total TFRs for all women and for women by race and Hispanic origin are based on population estimates derived from the 2010 census, as of July 1, 2019 (14).

The educational attainment levels in ASEC are based on the highest level of school completed or the highest degree received by the respondent at the time of the survey, with the CPS ASEC categories comparable with those on the revised birth certificate $(10,11)$. Information on data from the 2019 ASEC is available from the ASEC Technical Documentation (15).

Rates shown in this report may differ from rates computed on the basis of other population estimates.

Unless otherwise specified, references to differences in TFRs indicate that the difference is statistically significant, based on a pairwise comparison, which was assessed using a two-tailed $z$ test with an alpha level of 0.05 . An asterisk $\left(^{*}\right)$ is shown in place of a rate for which the relative standard error is $23 \%$ or more, which is not considered statistically reliable $(9,16)$.

For information on the testing of rates based on CPS ASEC population estimates, see "Random variation and confidence intervals for natality data" and "Random variation and significance testing for population subgroups" in the "User Guide to the 2010 Natality Public Use File" (16). For the CPS standard error parameters used, see the ASEC Technical Documentation (15).

\section{Results}

\section{Total fertility rates, by maternal educational attainment}

- In 2019, the U.S. TFR was 1,705 expected births per 1,000 women. TFRs by educational attainment ranged from a low of 1,284 for women with a bachelor's degree to a high of 2,791 for women with a 12th grade education or less (Table, Figure 1). In other words, women with a 12th grade education or less would be expected to have 2.8 births on average over their lifetimes, or more than one additional birth compared with 1.3 births on average for women with an associate's or bachelor's degree.

- TFRs were highest among women with a 12th grade education or less $(2,791)$ and declined with increasing education through those with an associate's degree $(1,312)$ and bachelor's degree $(1,284)$. TFRs then increased for women with a master's degree $(1,405)$ and those with a doctorate or professional degree $(1,523)$, although the increase from master's to doctorate or professional degree was not significant. 
Figure 1. Total fertility rate for all women, by educational attainment of mother: United States, 2019

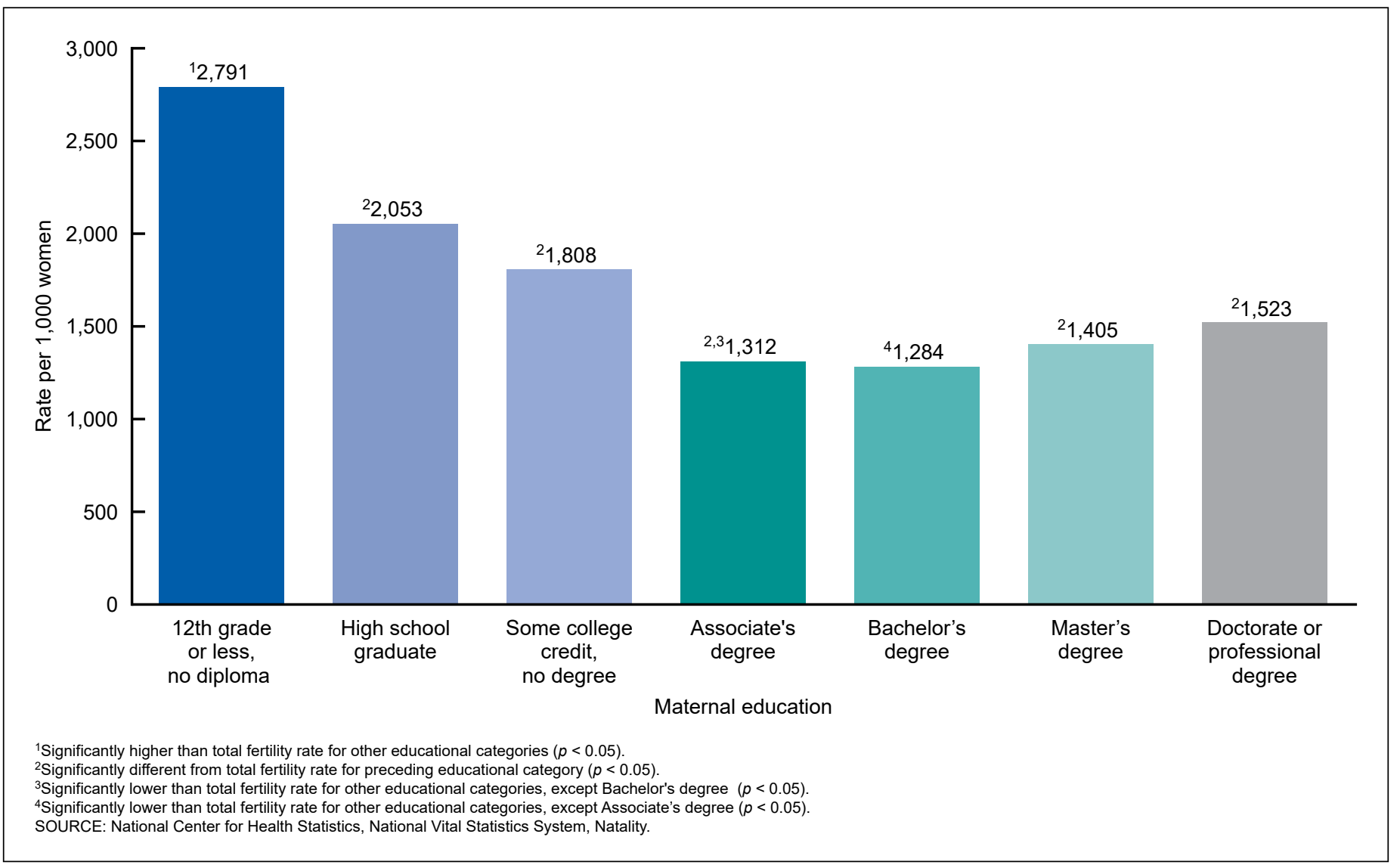

\section{Total fertility rates, by maternal educational attainment and race and Hispanic origin}

- By race and Hispanic origin, the highest overall TFR was for Hispanic women $(1,939)$ followed by non-Hispanic black $(1,774)$ and non-Hispanic white $(1,610)$ women (Table).

- Among non-Hispanic white women, TFRs by educational attainment ranged from a low of 1,307 expected births for women with a bachelor's degree to a high of 2,509 for women with a 12th grade education or less. In other words, non-Hispanic white women with a 12th grade education or less could be expected to have almost twice as many births (2.5 births) as non-Hispanic white women with a bachelor's degree (1.3) (Table, Figure 2).

- TFRs for non-Hispanic black women ranged from a low of 1,038 births for women with a master's degree to a high of 2,688 births for women with a 12th grade education or less, a difference of more than twice as many births for women with a 12th grade education or less compared with women with a master's degree (Table, Figure 3).

- Among Hispanic women, TFRs ranged from a low of 1,189 for women with an associate's degree, to a high of 3,025 for women with a 12th grade education or less, a difference of more than twice as many births for women with a 12th grade education or less compared with women with an associate's degree (Table, Figure 4).
- Patterns in TFRs by educational attainment differed somewhat for the three race and Hispanic-origin groups.

- For non-Hispanic white women, TFRs declined from 2,509 for women with a 12th grade education or less to 1,823 for women with a high school degree, 1,782 for women with some college but no degree (the difference in the rates between women in this category and the preceding category was not significant), 1,359 for women with an associate's degree, and 1,307 for women with a bachelor's degree. TFRs then rose $15 \%$ to 1,508 for women with a master's degree and to 1,545 for women with a doctorate or professional degree (the increase from master's to doctorate or professional degree was not significant).

- TFRs for non-Hispanic black women declined with increasing education: 2,688 for women with a 12 th grade education or less, 2,381 for women with a high school degree, 1,822 for women with some college credit but no degree, 1,459 for women with an associate's degree, 1,111 for women with a bachelor's degree, and 1,038 for women with a master's degree. The TFR for nonHispanic black women with a doctorate or professional degree was not statistically reliable and is not shown.

- For Hispanic women, the rate declined from 3,025 for women with a 12th grade education or less to 2,378 for women with a high school degree to 1,998 for women with some college but no degree to 1,189 for women 
Figure 2. Total fertility rate for non-Hispanic white women, by educational attainment of mother: United States, 2019

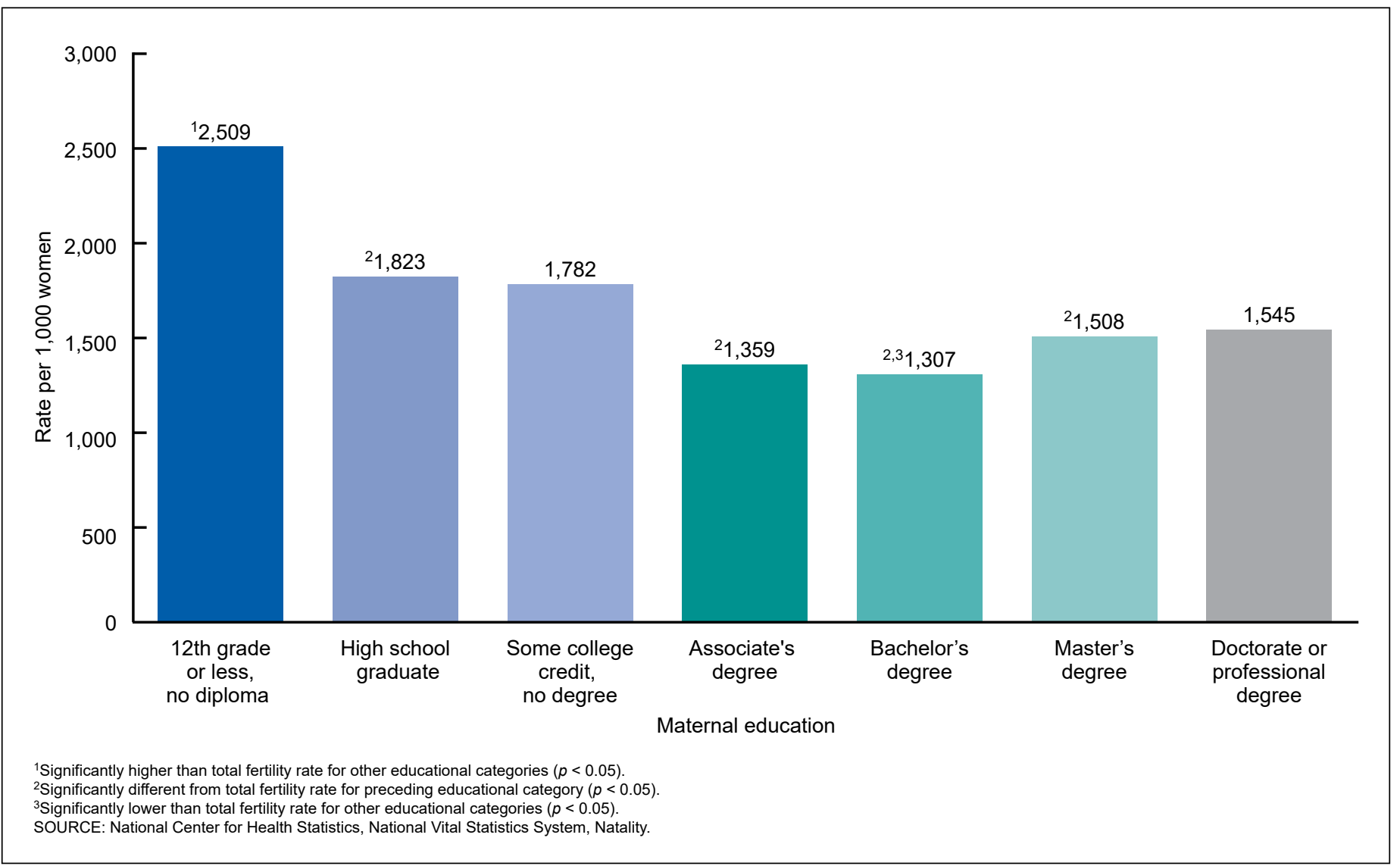

Figure 3. Total fertility rate for non-Hispanic black women, by educational attainment of mother: United States, 2019

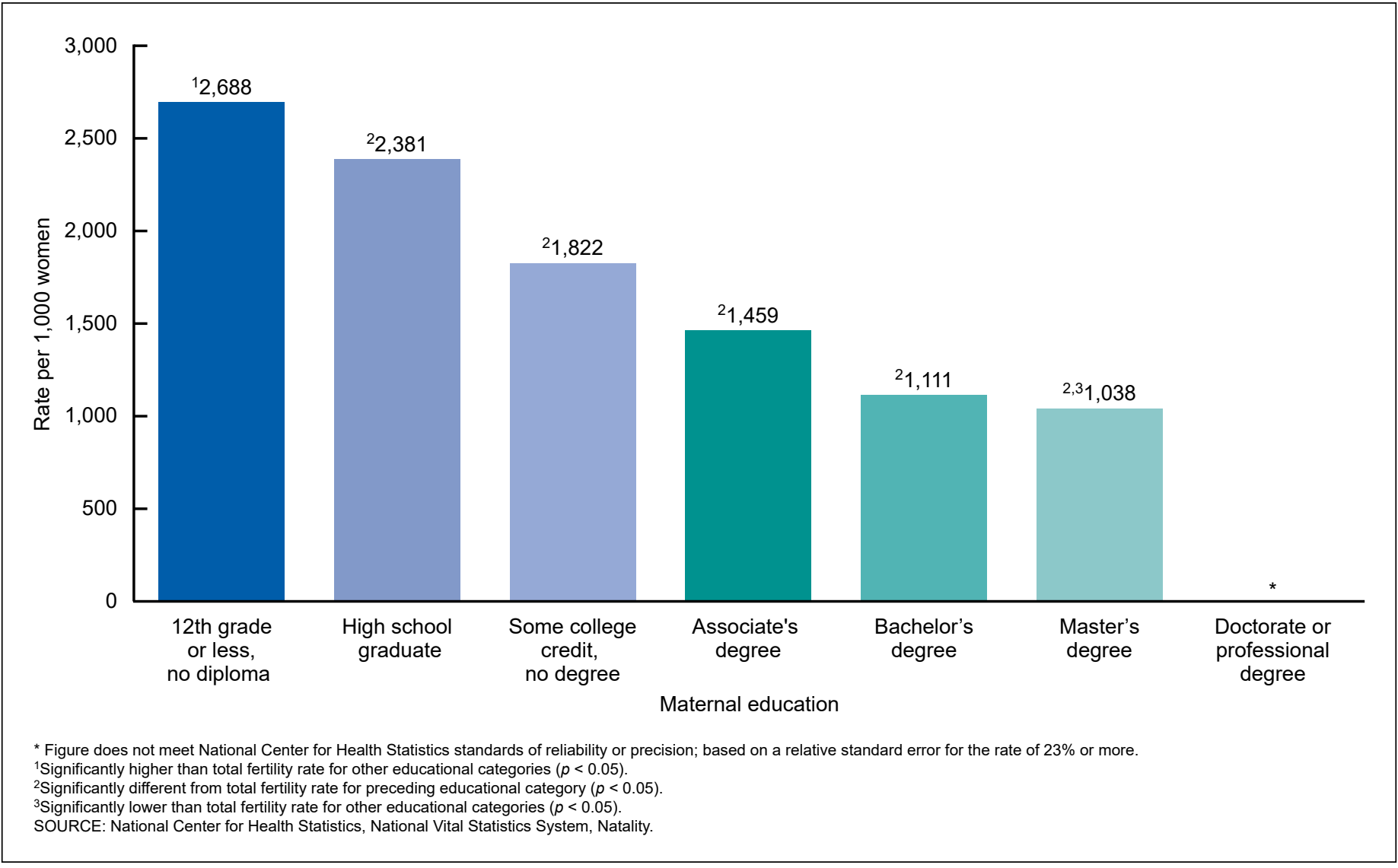


Figure 4. Total fertility rate for Hispanic women, by educational attainment of mother: United States, 2019

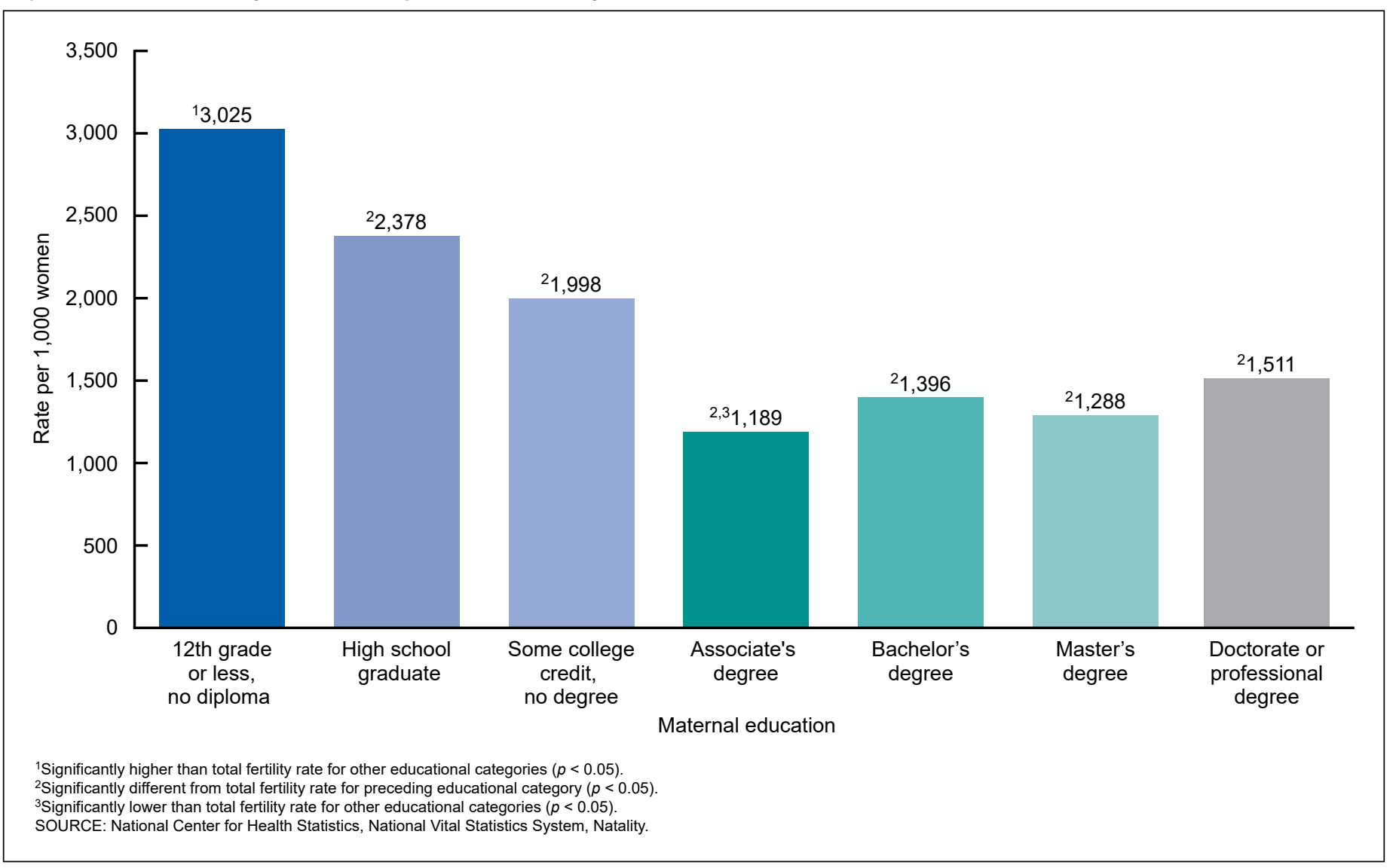

with an associate's degree. TFRs then rose to 1,396 for women with a bachelor's degree, declined slightly for women with a master's degree to 1,288, and then rose again to 1,511 for women with a doctorate or professional degree.

- $\quad$ Patterns of TFRs by level of educational attainment differed by race and Hispanic origin. TFRs were lower among nonHispanic white and non-Hispanic black women compared with Hispanic women for women with less than a high school education and those with some college but no degree (Table, Figure 5). However, TFRs for women with a high school degree were lower among non-Hispanic white women compared with the other two groups. Patterns among women with a bachelor's degree or master's degree were similar, with lower TFRs among non-Hispanic black women compared with non-Hispanic white and Hispanic women. TFRs were similar for non-Hispanic white and Hispanic women with a doctorate or professional degree.

\section{Summary}

This report shows the general patterns and variations in total fertility rates by maternal educational attainment by race and Hispanic origin. In general, TFRs were higher for women with lower educational attainment and lower for women with higher educational attainment. For all women, TFRs ranged from a low of 1,284 births for women with a bachelor's degree to a high of 2,791 births for women with a 12th grade education or less, a difference of more than one additional birth over a lifetime for a woman at the lowest educational level. Somewhat different patterns in TFRs by educational level were observed for all women compared with those observed by race and Hispanicorigin group. For all women, TFRs by educational attainment declined from the lowest educational level through associate's degree or bachelor's degree and then rose from associate's degree or bachelor's degree through doctorate or professional degree. Similarly, for non-Hispanic white women, TFRs generally declined from the lowest educational level through bachelor's degree and then rose through the advanced degrees. For Hispanic women, TFRs generally declined from the lowest educational level through an associate's degree and then generally rose through the advanced degrees, whereas among non-Hispanic black women, TFRs declined from the lowest educational level through master's degree (the rate for women with a doctorate or professional degree was not statistically reliable).

\section{Limitations}

The total fertility rate assumes that there is no change in the age-specific fertility rates for women over the span of their reproductive lifetimes. The TFR is affected by changes in the timing of childbearing over women's reproductive lifetimes. The TFR may be lowered by delaying childbearing to older ages 
Figure 5. Total fertility rate, by educational attainment and race and Hispanic origin of mother: United States, 2019

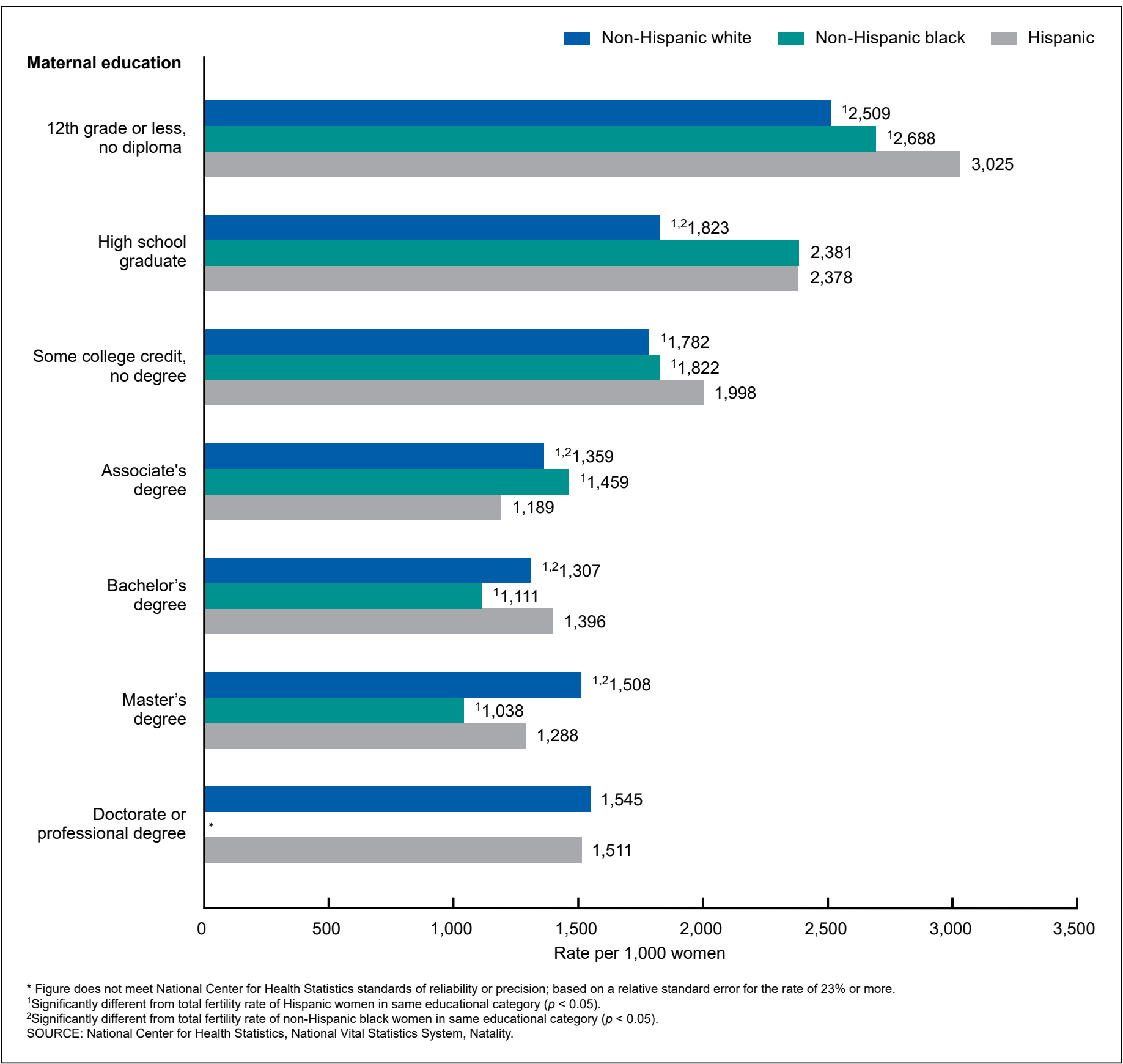

among women who have completed or who have planned to attain higher levels or degrees of education.

Additionally, the rates shown in this report are based on the level of education attained by the mother at the time of delivery and reflect the chance of giving birth by her current age and education. The mother may have already completed her education, her education may have ended with the birth that occurred, or she may go on to attain a higher level of education over her lifetime. As with the expected number of births, these rates may not necessarily reflect the total or final educational attainment of the mother.

\section{Conclusion}

Maternal educational attainment continues to be associated with fertility. Over the last several decades, birth and fertility rates have generally declined in the United States, both overall and for each race and Hispanic-origin group $(8,17)$. At the same time, the educational attainment of mothers has risen $(3,4)$. As shown in this report, TFRs differ by level of educational attainment and are generally higher for women with a lower level of educational attainment compared with women with higher educational attainment. TFRs by educational attainment also differ by race and Hispanic origin. Fertility rates by education can provide 
insight into the variation and change in fertility for women giving birth overall and for more specified population groups.

\section{References}

1. Martinez GM, Daniels K, Febo-Vazquez I. Fertility of men and women aged 15-44 in the United States: National Survey of Family Growth, 2011-2015. National Health Statistics Reports; no 113. Hyattsville, MD: National Center for Health Statistics. 2018. Available from: https://www.cdc.gov/nchs/ data/nhsr/nhsr113.pdf.

2. Daniels K, Daugherty J, Jones J, Mosher W. Current contraceptive use and variation by selected characteristics among women aged 15-44: United States, 2011-2013. National Health Statistics Reports; no 86. Hyattsville, MD: National Center for Health Statistics. 2015. Available from: https://www.cdc.gov/nchs/data/nhsr/nhsr086.pdf.

3. Mathews TJ, Ventura SJ. Birth and fertility rates by educational attainment: United States, 1994. Monthly Vital Statistics Reports; vol 45 no 10, supp. Hyattsville, MD: National Center for Health Statistics. 1997. Available from: https://www.cdc.gov/nchs/data/mvsr/supp/mv45_10s.pdf.

4. Mathews TJ, Hamilton BE. Educational attainment of mothers aged 25 and over: United States, 2017. NCHS Data Brief, no 332. Hyattsville, MD: National Center for Health Statistics. 2019. Available from: https://www.cdc.gov/nchs/ data/databriefs/db332-h.pdf.

5. Martin JA, Hamilton BE, Osterman MJK, Driscoll AK, Drake P. Births: Final data for 2016. National Vital Statistics Reports; vol 67 no 1. Hyattsville, MD: National Center for Health Statistics. 2018. Available from: https://www.cdc. gov/nchs/data/nvsr/nvsr67/nvsr67_01.pdf.

6. National Center for Health Statistics. User guide to the 2016 natality public use file. Hyattsville, MD. Available from: https://ftp.cdc.gov/pub/Health_Statistics/NCHS/Dataset_ Documentation/DVS/natality/UserGuide2016.pdf.

7. Martin JA, Hamilton BE, Sutton PD, Ventura SJ, Menacker F, Munson ML. Births: Final data for 2003. National Vital Statistics Reports; vol 54 no 2. Hyattsville, MD: National Center for Health Statistics. 2005. Available from: https:// www.cdc.gov/nchs/data/nvsr/nvsr54/nvsr54_02.pdf.

8. Martin JA, Hamilton BE, Osterman MJK, Driscoll AK. Births: Final data for 2019. National Vital Statistics Reports; vol 70 no 2. Hyattsville, MD: National Center for Health Statistics. 2021. D0I: https://stacks.cdc.gov/view/cdc/100472.

9. National Center for Health Statistics. User guide to the 2019 natality public use file. Hyattsville, MD. Available from: https://ftp.cdc.gov/pub/Health_Statistics/NCHS/Dataset_ Documentation/DVS/natality/UserGuide2019-508.pdf.

10. National Center for Health Statistics. U.S. standard certificate of live birth. 2003. Available from: https://www.cdc.gov/ nchs/data/dvs/birth11-03final-ACC.pdf.

11. National Center for Health Statistics. Report of the panel to evaluate the U.S. standard certificates. 2000. Available from: https://www.cdc.gov/nchs/data/dvs/panelreport_acc.pdf.
12. Office of Management and Budget. Revisions to the standards for the classification of federal data on race and ethnicity. Fed Regist 62(210):58782-90. 1997.

13. U.S. Census Bureau. Microdata access. 2019 Current Population Survey Annual Social and Economic (ASEC) Supplement-March 2020. Available from: https://data. census.gov/mdat/\#/.

14. U.S. Census Bureau. 2019 population estimates. Annual state resident population estimates for 6 race groups ( 5 race alone groups and one multiple-race group) by age, sex, and Hispanic origin: April 1, 2010 to July 1, 2019 (SCEST2019-ALLDATA6). 2019. Available from: https://www2. census.gov/programs-surveys/popest/tables/2010-2019/ state/asrh/sc-est2019-alldata6.csv.

15. U.S. Census Bureau. Current Population Survey, 2019 Annual Social and Economic (ASEC) Supplement. 2019. Available from: https://www2.census.gov/programs-surveys/ cps/techdocs/cpsmar19.pdf.

16. National Center for Health Statistics. User guide to the 2010 natality public use file. Hyattsville, MD. Available from: https://ftp.cdc.gov/pub/Health_Statistics/NCHS/Dataset_ Documentation/DVS/natality/UserGuide2010.pdf.

17. Martin JA, Hamilton BE, Osterman MJK, Driscoll AK, Mathews TJ. Births: Final data for 2015. National Vital Statistics Reports; vol 66 no 1. Hyattsville, MD: National Center for Health Statistics. 2017. Available from: https:// www.cdc.gov/nchs/data/nvsr/nvsr66/nvsr66_01.pdf.

\section{Detailed Table}

Total fertility rates for women, by educational attainment and race and Hispanic origin of mother: United States, 2019 . . . . . . . . . . . . . . . . . . . . . . . . . 


\section{Table. Total fertility rates for women, by educational attainment and race and Hispanic origin of mother: United States, 2019}

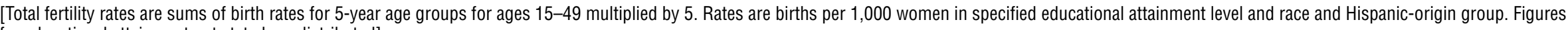
for educational attainment not stated are distributed]

\begin{tabular}{|c|c|c|c|c|c|c|c|c|}
\hline $\begin{array}{c}\text { Race and Hispanic origin } \\
\text { of mother }\end{array}$ & $\begin{array}{c}\text { Total } \\
\text { (95\% confidence } \\
\text { interval) }\end{array}$ & $\begin{array}{l}\text { 12th grade or less, } \\
\text { no diploma } \\
\text { (95\% confidence } \\
\text { interval) }\end{array}$ & 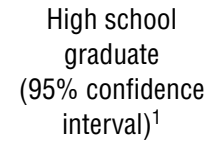 & $\begin{array}{l}\text { Some college credit, } \\
\text { no degree } \\
\text { (95\% confidence } \\
\text { interval) }\end{array}$ & $\begin{array}{l}\text { Associate's degree } \\
\text { (95\% confidence } \\
\text { interval) })^{2}\end{array}$ & $\begin{array}{c}\text { Bachelor's degree } \\
\text { (95\% confidence } \\
\text { interval) })^{3}\end{array}$ & $\begin{array}{l}\text { Master's degree } \\
(95 \% \text { confidence } \\
\text { interval })^{4}\end{array}$ & $\begin{array}{c}\text { Doctorate or } \\
\text { professional degree } \\
\text { (95\% confidence } \\
\text { interval) })^{5}\end{array}$ \\
\hline All races and origins ${ }^{6}$. & $\begin{array}{r}1,705 \\
(1,704.2-1,705.8)\end{array}$ & $\begin{array}{r}72,791 \\
(2,720.2-2,861.8)\end{array}$ & $\begin{array}{r}82,053 \\
(2,028.3-2,077.7)\end{array}$ & $\begin{array}{r}81,808 \\
(1,781.5-1,834.5)\end{array}$ & $\begin{array}{r}8,91,312 \\
(1,288.4-1,335.6)\end{array}$ & $\begin{array}{r}101,284 \\
(1,268.6-1,299.4)\end{array}$ & $\begin{array}{r}81,405 \\
(1,377.7-1,432.3)\end{array}$ & $\begin{array}{r}81,523 \\
(1,464.2-1,581.8)\end{array}$ \\
\hline Non-Hispanic white ${ }^{11}$. & $\begin{array}{r}1,610 \\
(1,609.0-1,611.0)\end{array}$ & $\begin{array}{r}7,122,509 \\
(2,394.3-2,623.7)\end{array}$ & $\begin{array}{r}8,12,131,823 \\
(1,790.8-1,855.2)\end{array}$ & $\begin{array}{r}121,782 \\
(1,743.6-1,820.4)\end{array}$ & $\begin{array}{r}8,12,131,359 \\
(1,326.0-1,392.0)\end{array}$ & $\begin{array}{r}8,12-141,307 \\
(1,287.4-1,326.6)\end{array}$ & $\begin{array}{r}8,12,131,508 \\
(1,468.4-1,547.6)\end{array}$ & $\begin{array}{r}1,545 \\
(1,472.6-1,617.4)\end{array}$ \\
\hline Non-Hispanic black ${ }^{11}$. & $\begin{array}{r}1,774 \\
(1,771.9-1,776.1)\end{array}$ & $\begin{array}{r}7,122,688 \\
(2,530.3-2,845.7)\end{array}$ & $\begin{array}{r}8,152,381 \\
(2,315.4-2,446.6)\end{array}$ & $\begin{array}{r}8,121,822 \\
(1,769.7-1,874.3)\end{array}$ & $\begin{array}{r}8,12,151,459 \\
(1,372.7-1,545.3)\end{array}$ & $\begin{array}{r}8,12,151,111 \\
(1,071.8-1,150.2)\end{array}$ & $\begin{array}{r}8,12,14,151,038 \\
(977.5-1,098.5)\end{array}$ & * \\
\hline Hispanic ${ }^{16}$ & $\begin{array}{r}1,939 \\
(1,937.2-1,940.8)\end{array}$ & $\begin{array}{r}7,13,153,025 \\
(2,921.0-3,129.0)\end{array}$ & $\begin{array}{r}8,152,378 \\
(2,328.2-2,427.8)\end{array}$ & $\begin{array}{r}8,13,151,998 \\
(1,941.4-2,054.6)\end{array}$ & $\begin{array}{r}8,13-151,189 \\
(1,149.2-1,228.8)\end{array}$ & $\begin{array}{r}8,13,151,396 \\
(1,352.3-1,439.7)\end{array}$ & $\begin{array}{r}8,13,151,288 \\
(1,214.6-1,361.4)\end{array}$ & $\begin{array}{r}{ }^{8} 1,511 \\
(1,313.3-1,708.7)\end{array}$ \\
\hline
\end{tabular}

${ }^{*}$ Figure does not meet National Center for Health Statistics standards of reliability or precision; based on a relative standard error for the rate of $23 \%$ or more.

Includes GED.

2Includes Associate of Arts and Associate of Science.

Includes Bachelor of Arts and Bachelor of Science.

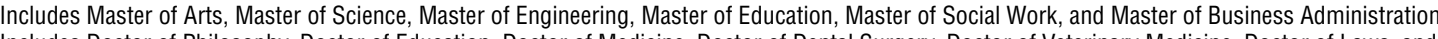

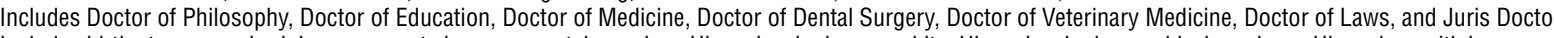

.

Significantly highor to

"Significantly diferent from total fertity rate for preceding educational category of women in same race and Hispanic-origin group $(p<0.05)$.

'Significantly lower than total fertily rate for other educational cacovolies of women in same race and Hispanic-origin group, except Bachelor's degree $(p<0.05)$.

mene are classified by race. Race categories are consistent with the 1997 office of Management and

Budget standards and show only single race. Single race is defined as only one race reported on the birth cerlificate.

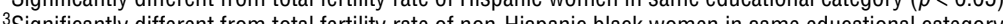

作

作

SOURCE: National Center for Health Statistics, National Vital Statistics System, Natality. 


\section{U.S. DEPARTMENT OF \\ HEALTH \& HUMAN SERVICES}

FIRST CLASS MAIL

POSTAGE \& FEES PAID

$\mathrm{CDC} / \mathrm{NCHS}$

Centers for Disease Control and Prevention

PERMIT NO. G-284

National Center for Health Statistics

3311 Toledo Road, Room 4551, MS P08

Hyattsville, MD 20782-2064

OFFICIAL BUSINESS

PENALTY FOR PRIVATE USE, $\$ 300$

For more NCHS NVSRs, visit:

https://www.cdc.gov/nchs/products/nvsr.htm.

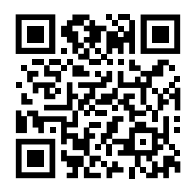

National Vital Statistics Reports, Vol. 70, No. 5, May 12, 2021

\section{Contents}

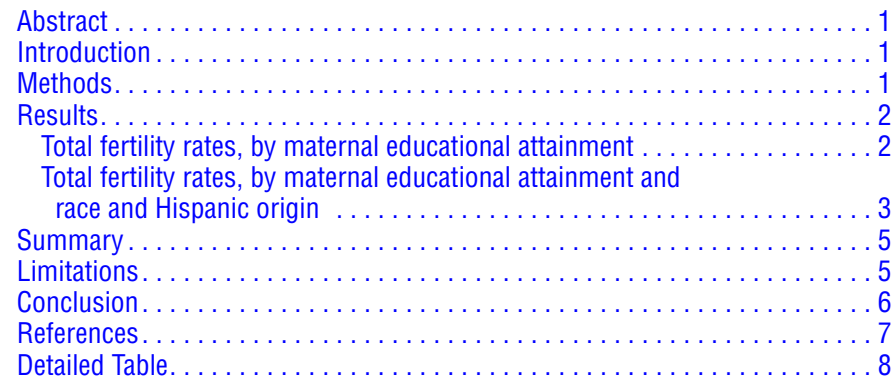

\section{Acknowledgments}

This report was prepared under the general direction of Steven Schwartz, Director of the Division of Vital Statistics (DVS); Isabelle Horon, Acting Associate Director for Science, DVS, and Chief, Reproductive Health Branch (RSB); and Joyce Martin, Team Leader, RSB Birth Team. The author would like to acknowledge the contributions of T.J. Mathews for his review and comments on early drafts of this report. This report was edited and produced by NCHS Office of Information Services, Information Design and Publishing Staff: Jen Hurlburt edited the report and typesetting and graphics were done by Erik L. Richardson.

\section{Suggested citation}

Hamilton BE. Total fertility rates, by maternal educational attainment and race and Hispanic origin: United States, 2019. National Vital Statistics Reports; vol 70 no 5. Hyattsville, MD: National Center for Health Statistics. 2021. DOI: https://doi.org/10.15620/cdc:105234.

\section{Copyright information}

All material appearing in this report is in the public domain and may be reproduced or copied without permission; citation as to source, however, is appreciated.
National Center for Health Statistics

Brian C. Moyer, Ph.D., Director

Amy M. Branum, Ph.D., Acting Associate Director for Science

Division of Vital Statistics

Steven Schwartz, Ph.D., Director Isabelle Horon, Dr.P.H., Acting Associate Director for Science

For e-mail updates on NCHS publication releases, subscribe online at: https://www.cdc.gov/nchs/email-updates.htm. For questions or general information about NCHS: Tel: 1-800-CDC-INFO (1-800-232-4636) • TTY: 1-888-232-6348 Internet: https://www.cdc.gov/nchs • Online request form: https://www.cdc.gov/info • CS323483 